九州大学学術情報リポジトリ

Kyushu University Institutional Repository

\title{
RNA Interference Induction by Long Hairpin dsRNAs Expressed from Chromosomal DNA of Bombyx mori Cells
}

Lee, Jae Man

Laboratory of Silkworm Sciences, Kyushu University Graduate School of Bioresource and Bioenvironmental Sciences

Kojin, Yoshito

Laboratory of Silkworm Sciences, Kyushu University Graduate School of Bioresource and Bioenvironmental Sciences

Tatsuke, Tsuneyuki

Laboratory of Silkworm Sciences, Kyushu University Graduate School of Bioresource and Bioenvironmental Sciences

Mon, Hiroaki

Laboratory of Silkworm Sciences, Kyushu University Graduate School of Bioresource and Bioenvironmental Sciences

他

https://doi.org/10.5109/25203

出版情報: 九州大学大学院農学研究院紀要. 57 (2)，pp.441-445，2012-09-20. Faculty of Agriculture, Kyushu University

バージョン :

権利関係 : 


\title{
RNA Interference Induction by Long Hairpin dsRNAs Expressed from Chromosomal DNA of Bombyx mori Cells
}

\author{
Jae Man LEE ${ }^{1}$, Yoshito KOJIN ${ }^{1}$, Tsuneyuki TATSUKE ${ }^{1}$, Hiroaki MON ${ }^{1}$, \\ Yoshitaka MIYAGAWA ${ }^{2}$ and Takahiro KUSAKABE ${ }^{1 *}$
}

Laboratory of Silkworm Sciences, Kyushu University Graduate School of Bioresource and Bioenvironmental Sciences, 6-10-1 Hakozaki, Fukuoka 812-8581, Japan

(Received April 27, 2012 and accepted May 10, 2012)

\begin{abstract}
RNA interference (RNAi) triggered by long double-stranded RNA (dsRNA) transcribed from chromosomal DNA has a lot of advantages in high-throughput analyses of gene function. In this report, we have constructed Gateway®-based RNAi induction vectors, by which we efficiently integrated expression cassettes for long hairpin dsRNA into chromosomal DNA of Bombyx mori cells. RNAi induced by the hairpin dsRNAs using our constructs decreased a reporter gene activity by approximately 70-80\% in cultured $B$. mori cells.
\end{abstract}

Keywords: Bombyx mori, dsRNA, Reporter expression, RNA interference, siRNA

\section{INTRODUCTION}

In insect, exogenously introduced long doublestranded RNA (dsRNA) efficiently induce RNA intereference (RNAi) (Lopez-Martinez et al., 2012) like plants (Garcia-Perez et al., 2004) and nematodes (Parrish et al., 2000). This is marked differenceis to mammalian cells in which long dsRNAs trigger sequence non-specific gene silencing by activating the PKR and RNase L pathways (Gil and Esteban, 2000). RNAi can be successfully induced in cultured silkworm cells (Fujita et al., 2009; Tomimoto et al., 2012) or embryos, but there are a few reports on gene silencing at the larval stage (Quan et al., 2002; Tabunoki et al., 2004; Huang et al., 2007; Hossain et al., 2008; Liu et al., 2008; Masumoto et al., 2009; Pan et al., 2009). Furthermore, it is really difficult to achieve a successful phenotype caused by RNAi in some tissues of Bombyx mori (Terenius et al., 2011). A possible reason for this inefficient RNAi induction by the injection of dsRNA into larvae is due to the difficulty of RNA delivery into silkworm organs or tissues.

One of the most popular method to archieve efficient RNAi induction in many organisms is to express hairpin dsRNA from chromosome (Lee et al., 2003; Miki et al., 2004; Szulc et al., 2006). To date, characteristic vectors have been constructed with an inverted repeat (IR) sequence encoding hairpin dsRNA. However, these take a long time to construct and meet with difficulties due to their structural instability in host cells. In the postgenome era, high-throughput vectors for efficient gene silencing are keenly needed; these would develop efficient RNAi system exploiting long dsRNA transcribed from chromosomes. The required features for these RNAi

\footnotetext{
Laboratory of Silkworm Sciences, Kyushu University Graduate School of Bioresource and Bioenvironmental Sciences, 6-10-1 Hakozaki, Fukuoka 812-8581, Japan

Department of Developmental Biology, National Research Institute for Child Health and Development, 2-10-1, Okura, Setagaya-ku, Tokyo 157-8535, Japan

* Correspondence author (E-mail: kusakabe@agr.kyushu-u.ac.jp)
}

systems are (1) high efficiency of gene silencing, (2) the convenience for constructing tools, and (3) the constancy of inducing RNAi.

Here, we have constructed a silkworm gene knockdown system using a Gateway®-based plasmid that expresses long hairpin dsRNA. The long hairpin dsRNA expressed from silkworm chromosome decreased a reporter gene activity by approximately $70-80 \%$ in BmN4 cells.

\section{MATERIALS AND METHODS}

\section{Cell culture}

B. mori BmN4 cells (from a stock of laboratory of Insect Pathology and Microbial Control, Faculty of Agriculture, Kyushu University Graduate School) was maintained in IPL-41 insect medium (Sigma Chemical) supplemented with $10 \%$ fetal bovine serum (GIBCO Invitrogen) at $27^{\circ} \mathrm{C}$. Before use for transfection, the medium was replaced by Sf-900 II serum free medium (Invitrogen).

\section{Construction of mediators for dsRNA expression vectors}

The organization of dsRNA expression constructs (named pAladdinGate, abbreviated to pAG) used in this study is shown in Figure 1A. The plasmid pPigBase1.4 (DDBJ AB254131), which contains piggyBac transposase sequence (piggyBac L/R fragment) and the multiple cloning site (MCS) sequences, was used as a basic plasmid for the construction of pAG vectors.

Synthetic GFP-Zeocin resistance fusion gene was amplified from pIZT/V5-His plasmid (Invitrogen) by PCR with the primers GFP-Zeocin-5 and GFP-Zeocin-3 (Table 1), and introduced into a ScaI site of pPigbase1.4. The resulting plasmid was named pPig1.4Zeo. To construct the Gateway®-based dsRNA expression cassettes, the destination plasmid pBmHSC70-4DEST (Lee et al., 2008), which contain insect promoters and attR1ccdB-attR2 cassettes, were used as forward oriented 
A
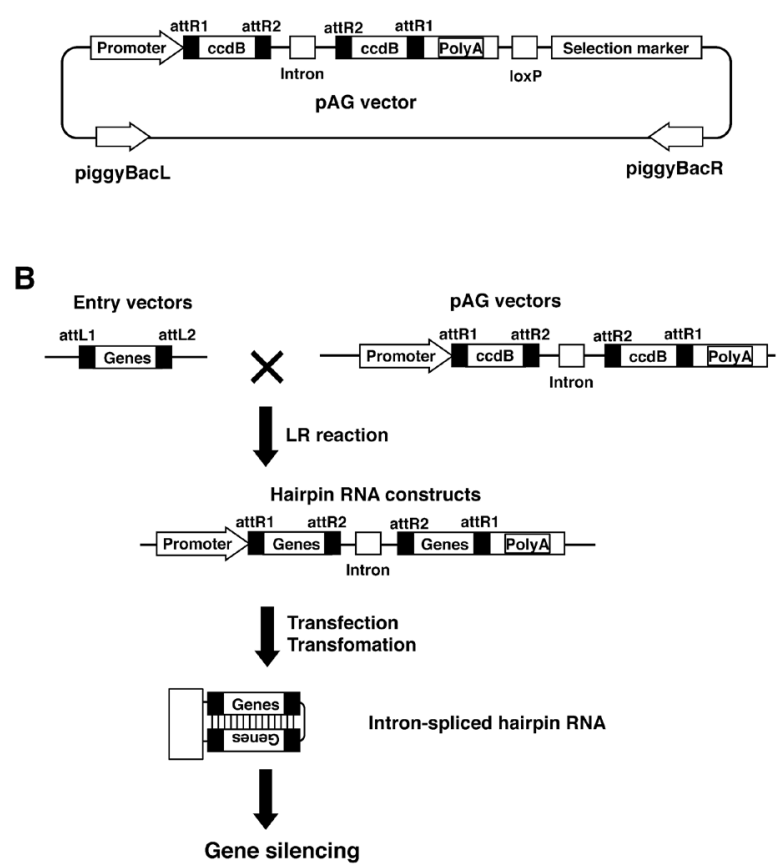

Fig. 1. Construction of the hairpin dsRNA expression plasmids, pAG. (A) Molecular structure of Gateway ${ }^{\circledR}-$ based pAG vectors. (B) Construction strategy for dsRNA expression plasmid using the Gateway® system.

DEST cassettes. The pZhscinIDEST, which contains the first intron of the BmHSC70-4 gene (Lee et al., 2008) and reverse orientated DEST cassette (with attR2-ccdBattR1 cassettes), were digested with $\mathrm{XbaI}$ and $\mathrm{BamHI}$, followed by blunting and cloning into the XhoI and XbaI blunt-ended site of the pBmHSC70-4DEST plasmid. The resulting dsRNA expression cassettes, pBmHSC704IRDEST, was digested with ApaI and SacI, blunt-ended, and cloned into a NotI blunt-ended site of pPig1.4Zeo. Thus formed construct ( $\mathrm{pAG}$ ) was subjected to the Gateway® LR reaction with entry vectors (Fig. 1B) using LR Clonase ${ }^{\mathrm{TM}}$ Enzyme Mix (Invitrogen) according to the protocols recommended in manufacturer's manual.

\section{Construction of entry clones}

All entry clones were constructed using $\mathrm{pENTR}^{\mathrm{TM}} 11$ from Invitrogen. To obtain the partial luciferase fragments, a full luciferase cDNA of pSK8Fb-Luc vector (kindly provided by Professor Hisanori Bando of Hokkaido University Graduate School) was roughly divided into 3 regions: $593 \mathrm{bp}$ of 5'-fragment (F-Luc; 1 to 593), $721 \mathrm{bp}$ of middle-fragment (M-Luc; 588 to 1,308), and $360 \mathrm{bp}$ of 3'-fragment (L-Luc; 1,251 to 1,610). The F-Luc fragment was amplified using the primers F-Luc-5 and F-Luc-3-EcoRI (Table 1). After EcoRI digestion, the resulting fragment was inserted into an EcoRI and EcoRV site of $\mathrm{pENTR}^{\mathrm{TM}} 11$ (pENTR-F-Luc). The M-Luc fragment was amplified using the primers M-Luc-5-EcoRI and M-Luc-3 (Table 1), and inserted into an EcoRI and EcoRV site of pENTR ${ }^{\mathrm{TM}} 11$ (pENTR-M-Luc). The L-Luc fragment was amplified using the primers L-Luc-5 and L-Luc-3 (Table 1), and inserted into XmnI and EcoRV
Table 1. List of primers used for this study

\begin{tabular}{lc}
\hline Primer Nam & \multicolumn{1}{c}{ Primer Sequence (5'-3’ ) } \\
\hline F-Luc-5 & ATGGAAGACGCCAAAAACATAAAGAAA \\
F-Luc-3-EcoRI & GAGGAATTCATTATCAGTGCAATTGTTTTG \\
M-Luc-5-EcoRI & TAATGAATTCCTCTGGATCTACTGGGTTAC \\
M-Luc-3 & TCAACTATGAAGAAGTGTTCGTCTTCGTC \\
L-Luc-5 & GCTACATTCTGGAGACATAGCTTACTGGGA \\
L-Luc-3 & CTCTGATTTTTCTACGTACGAGTTTTCCGG \\
XDH1-5 & GGATTATTGAATGCTGAGGAAGATCCG \\
XDH1-3-XhoI & TCTCGAGGAAAAATTGGCTCTTGACTAG \\
pBS-T7 & TGAGCGCGCGTAATACGACTCACTATAGGG \\
DMC1-3 & TAATACGACTCACTATAGGGAACAAAAGCT \\
\hline
\end{tabular}

site of pENTR ${ }^{\mathrm{TM}} 11$ (pENTR-L-Luc). The entry clones pENTER-F-Luc, pENTER-M-Luc, pENTER-L-Luc, and the destination vectors (pAGs) prepared as described above were subjected to the Gateway reaction according to the protocols recommended in manufacturer's manual (Invitrogen). The final forms will be called pAG-F-Luc, pAG-M-Luc, and pAG-L-Luc, respectively.

Partial XDH1 (Xanthine dehydrogenase; GenBank Accession Number: AB060285) fragment used as a negative control sequence was amplified by PCR using the primers XDH1-5 and XDH1-3-XhoI (Table 1) using cDNA from ovary of silkworm w051 strain. The PCR fragment was inserted into a XhoI and XmnI site of pEN$\mathrm{TR}^{\mathrm{TM}} 11$ (pENTR-control). Partial GFP fragment, amplified by PCR using the primers GFP-5 and GFP-3 (Table 1), was inserted into a XmnI and EcoRV site of pEN$\mathrm{TR}^{\mathrm{TM}} 11$ (pENTR-GFP9900). The final vectors derived from the above constructs are named $\mathrm{pAG}-\mathrm{XDH}$ and pAG-GFP, respectively.

Final pPig1.4ZeoDEST-Luc plasmid for stable expression of luciferase was generated by Gateway reaction between the pENTR-Luc (Lee et al., 2008) and destination vector $\mathrm{pPig} 1.4 \mathrm{ZeoDEST}$. The pPig1.4ZeoDEST was generated by inserting an ApaI and SacI/blunt fragment of the pBmHSC70-4DEST (BmHSC70-4 promoter, attR1-ccdB-attR2 cassettes and polyadenylation sequence) (Lee et al., 2008) into a NotI blunt-ended site of pPig1.4Zeo.

\section{Preparation of double-stranded RNA}

Templates for transcription of dsRNA, used for transfection, were synthesized by two-step PCR from silkworm DMC1 sequence (Mon et al., 2004; GenBank Accession Number: NM_00104487) in pBluescript SK (+), using the primers pBS-T7 and DMC1-3 (Table 1) for the first step PCR. For the second PCR, the single primer pBS-T7 was used. The resulting PCR fragment possesses inverted terminal T7 promoters. Templates for the firefly luciferase dsRNA was amplified by the similar two-step PCR method (Sakashita et al., 2009). After phenol/chloroform extraction the DNA template was incubated in transcription reaction buffer (40 mM Tris-HCl buffer, pH7.5, $6 \mathrm{mM} \mathrm{MgCl}$, $10 \mathrm{mM}$ DTT, $10 \mathrm{mM} \mathrm{NaCl}, 2 \mathrm{mM}$ spermidine, $2 \mathrm{mM}$ dNTPs, $8 \mathrm{U}$ of RNase inhibitor, and $20 \mathrm{U}$ of T7 RNA 
polymerase) for $2 \mathrm{~h}$ at $37^{\circ} \mathrm{C}$. The RNA product (dsLuc and dsDmc 1) were purified, dissolved in $100 \mathrm{mM} \mathrm{HEPES}$, $\mathrm{pH} 7.0$, heat denatured for $5 \mathrm{~min}$ at $94^{\circ} \mathrm{C}$, and allowed to stand at room temperature for 30 min for annealing.

\section{Transient expression of reporter genes and trans- formation of cells}

BmN4 cells, or other cells indicated, at a concentration of $1 \times 10^{5}$ per well were transfected with appropriate materials by a lipofection method using the CellFECTIN reagent (Invitrogen) for $6 \mathrm{~h}$. The vectors pBmTCTP-Luc, pBmHSC70-4-Luc, and pOpIE-2- $\beta$-gal (Lee et al., 2008) were used for the transient expression of luciferase and $\beta$-galactosidase, respectively, as reporters. All constructs were purified using a Plasmid Mini kit (Qiagen) beforehand. The transfected cells were washed once with PBS and lastly incubated in IPL-41 medium supplemented with 10\% FBS. Appropriate times after incubation, the luciferase activity was measured by PicaGene ${ }^{\circledR}$ kit (Toyo Ink) using 1,253 Luminometer (Bio-Orbit). The cell extract was also used for measuring $\beta$-galactosidase activity essentially according to the method described previously (Ausubel et al., 1988).

To select the transformed cells constitutively expressing partial luciferase dsRNA (named as L16) and full luciferase gene (named as N4-Luc), BmN4 cells $\left(1 \times 10^{5}\right.$ per well) were seeded and co-transfected with $1 \mu \mathrm{g}$ of the transformation plasmid pAG-L-Luc or pPig1.4ZeoDESTLuc and $1 \mu \mathrm{g}$ of transposase expressing piggy Bac-helper plasmid pA3helper (Cary et al., 1989), using CellFECTIN. After $96 \mathrm{~h}$ of transfection, the cells were split at a ratio of $1: 5$ and selected for Zeocin-resistance in the medium containing $100 \mu \mathrm{g} / \mathrm{ml}$ Zeocin (Invitrogen) (Pfeifer et al., 1997; Yamamoto et al., 2004).

\section{RESULTS}

\section{RNAi with dsRNA in cultured BmN4 cells}

To investigate the RNAi efficiency in silkworm cells, a $1.6 \mathrm{kbp}$ dsRNA for firefly luciferase (dsLuc) was transfected into BmN4 cells with the luciferase and $\beta$-galactosidase expression plasmids (pBmTCTP-Luc and pOpIE-2- $\beta$-gal, respectively). As shown in Figure $2 \mathrm{~A}$, the cells gave no luciferase activity, when the dsRNA and reporter plasmid was co-transfected into BmN4 cells. However, when we transfected the dsLuc into the BmN4 cells stably expressing luciferase mRNA (N4-Luc), the level of the activity was suppressed only $>70 \%$ in contrast to the control (Fig. 2B, showing the patterns for dsRNA). These observations imply that the transfection efficiency of cultured silkworm cells was considerably low, and for this reason we developed a following new method for RNAi.

\section{Efficiency of hairpin dsRNA in BmN4 cells}

A series of vectors expressing hairpin dsRNAs were constructed with the pAG plasmids, which had two Gateway ${ }^{\circledR}$ recombination sites for introducing an arbitrary DNA fragment as IR. Upstream of this IR cassette, BmHsc70-4 promoter was located to express dsRNAs in
A

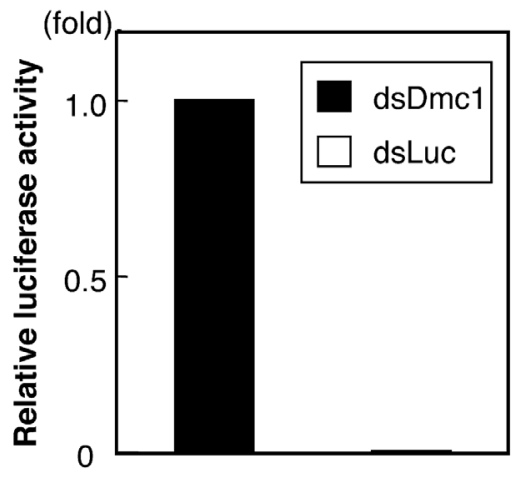

B

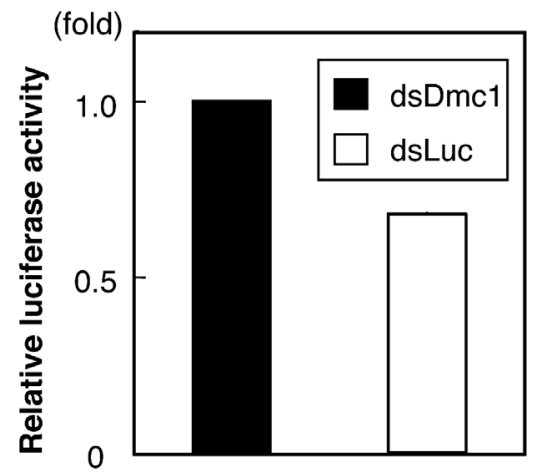

Fig. 2. Quantification of the efficiency of RNAi in cultured silkworm cells. Cells were seeded in $24-$ well plates $\left(0.7 \times 10^{5}\right.$ cells per well) and co-transfected with each $250 \mathrm{ng} / \mathrm{well}$ of luciferase- and $\beta$-galactosidase-expressing vectors (pBmTCTP-Luc and pOpIE-2- $\beta$-gal, respectively) as reporters, together with $100 \mathrm{ng} /$ well of dsRNA encoding DMC1 (dsDmc1 as a control) or luciferase (dsLuc). Four days after transfection, the cells were determined for the reporter activities. Each luciferase activity normalized by $\beta$-galactosidase activity was illustrated as a relative valu of the control $(=1.0)$. Average of three independent experiments with SD was indicated. (A) BmN4 cells. (B) Transformed BmN4 cells stably expressing luciferase (N4-Luc)

B. mori cells. BmHsc70-4 intron was set at internal loops, since it was expected that the presence of an intron might increase the genomic stability of IR transgene (Leach, 1994; Bi and Liu, 1996; Brown et al., 2003).

The rate of RNAi induction was previously noted to vary depending on the nucleotide sequence of trigger dsRNA (Parrish et al., 2000). To investigate this issue, pAG-F-Luc, pAG-M-Luc, and pAG-L-Luc were constructed to express hairpin dsRNA from the three partial luciferase sequences (forward, middle, and late), respectively. The resulting plasmids, as well as reporter vectors encoding luciferase and $\beta$-galactosidase (pBmTCTPLuc and pOpIE-2- $\beta$-gal, respectively) as reporters, were transfected into BmN4 cells, which were then measured for reporter activities. As shown in Fig. 3A, the RNAi activity induced by pAG-L-Luc was slightly higher than that induced by pAG-F-Luc or pAG-M-Luc. To a maximum degree, the luciferase activity was suppressed by $>70 \%$. These findings indicated that a luci- 
A

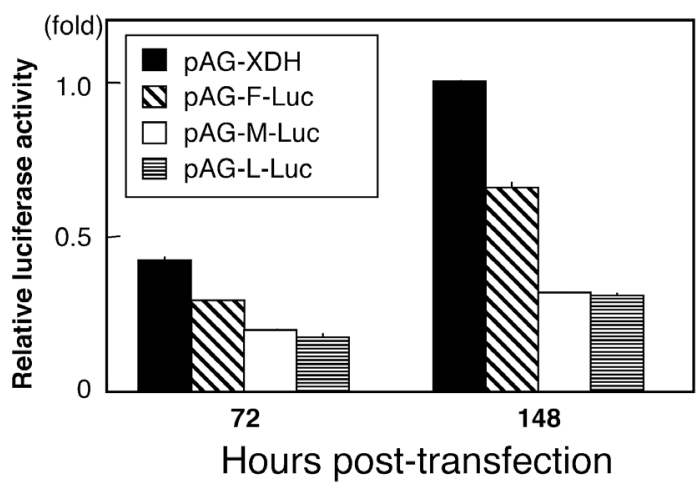

B

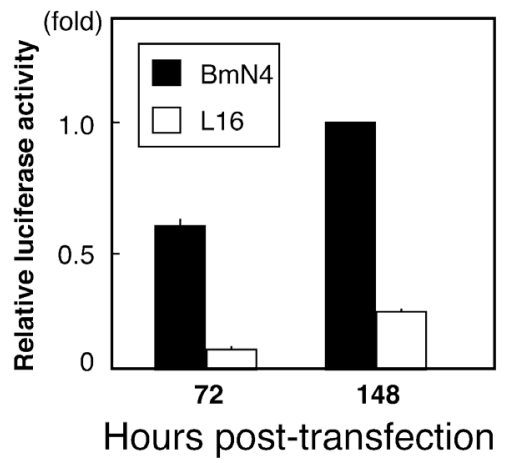

Fig. 3. Hairpin dsRNA is potent inducer of RNAi in cultured silkworm cells. (A) Luciferase gene $(1.6 \mathrm{kbp})$ was divided into 3 parts, F-Luc, M-Luc, and L-Luc, and each was inserted into pAG vector as detailed in MATERIALS AND METHODS. Each $250 \mathrm{ng}$ of the resulting pAG plasmids was co-transfected with $250 \mathrm{ng}$ of pBmTCTP-Luc and $30 \mathrm{ng}$ of pOpIE-2- $\beta$-gal into BmN4 cells. pAG-XDH was used as a control. At 72 and $148 \mathrm{~h}$ after transfection, the cells were measured for the luciferase activity. Each luciferase activity normalized by $\beta$-galactosidase activity was illustrated as a relative valu of the control at $148 \mathrm{~h}$ $(=1.0)$. Average of three independent experiments with SD was indicated. (B) L16 cells (transformed BmN4 cells to express stably L-Luc dsRNA, see text for details) and original BmN4 cells (control) were seeded as above, cotransfected with $250 \mathrm{ng}$ of pBmTCTP-Luc and $30 \mathrm{ng}$ of pOpIE-2- $\beta$-gal, and assayed for reporter activities. Other details are as those described in (A).

ferase cDNA sequence at the $\mathrm{L}$-Luc region 1,251 to 1,610 was the most effective for RNAi under our experimantal condition using pAG.

When IR was inserted into the BmN4 genome, its unstable structure may reduce the RNAi efficiency. This possibility was examined using the BmN4 cells established to express constitutively the hairpin dsRNA from the partial luciferase region corresponding to L-Luc; this newly transformed cell line will be tentatively called L16 in what follows. When transfected with vectors for reporter enzymes, L16 cells gave markedly reduced relative activity compared to the original BmN4 cells (Fig. 3B), indicating the occurrence of efficient RNAi. Although the relative luciferase activity in L16 cells was decreased by about $70 \%$ on day 7 after transfection, this RNAi efficiency was maintained even after about 100 days from setting the newly transformed cells (data not shown). On the basis of these findings, we concluded that pAG could stably induce RNAi from the BmN4 genome.

\section{DISCUSSION}

The BmN4 cell line was known as one of cultured cells with low transfection efficiency, like other silkwormderived cell lines. Therefore, BmN4 cells are difficult to induce efficient RNAi in with dsRNA or siRNA by silencing a target gene function in a nearly the whole cell population of transfected cells. However, the pAG vector has piggyBac recognition sequences to transpose IR transgene into a chromosome of the cell, and the resulting cells possessing the integrated copy of the IR structure can be selected by antibiotics.

Under the our experimental condition, the hairpin dsRNA transcribed from IR transgene on chromosomal DNA decreased a reporter luciferase activity by approximately $70-80 \%$. In many organisms, a complete knockdown is not required to produce a phenotype similar to its null-mutation. Therefore, our result indicated that simple use of pAG vectors facilely induced RNAi in the silkworm cells, so that a number of genes can be knocked down by this system. Although other studies have reported that expression plasmids encoding for long hairpin dsRNAs could be used in many organisms (Fujita et al., 2009; Tomimoto et al., 2012), knowledge concerning $B$. mori cells are of special importance, as this species provides the excellent biofactory that enables largescale production of recombinant proteins in commercial scale. Also for the scientific research on the silkworm genetics, the presently established pAG knockdown system must be useful tools.

\section{ACKNOWLEDGEMENTS}

This work was supported in part by a grant from the Ministry of Agriculture, Forestry, and Fisheries of Japan (Integrated research project for plant, insect and animal using genome technology INSECT-1201). We thank Dr. C. Aoki (Kyushu University Graduate School) for providing the BmN4 cell line.

\section{REFERENCES}

Ausubel, F. M., R. Brent, R. E. Kingston, D. D. Moore, J. G. Seidman, J. A. Smith, and K. Struhl 1988 In Current Protocols in Molecular Biology, John Willey \& Sons, Inc., New York. pp. 600

Bi, X., and L. F. Liu 1996 DNA rearrangement mediated by inverted repeats. Proc. Natl. Acad. Sci. USA, 93: 819-823

Brown, A. E., A. Crisanti, and F. Catteruccia 2003 Comparative analysis of DNA vectors at mediating RNAi in Anopheles mosquito cells and larvae. J. Exp. Biol., 206: 1817-1823

Cary, L. C., M. Goebel, B. G. Corsaro, H. G. Wang, E. Rosen, and M. J. Fraser 1989 Transposon mutagenesis of baculoviruses: analysis of Trichoplusia ni transposon IFP2 insertions within the FP-locus of nuclear polyhedrosis viruses. Virology, 172: 156-169

Fujita, K., A. Sagisaka, K. Tomimoto, J. Ishibashi, S. Imanishi, M. Yamakawa, and H. Tanaka 2009 DNA vector-based RNA 
interference in cell lines derived from Bombyx mori. Biosci. Biotechnol. Biochem., 73: 2026-2031

Garcia-Perez, R. D., H. V. Houdt, and A. Depicker 2004 Spreading of post-transcriptional gene silencing along the target gene promotes systemic silencing. Plant J., 38: 594-602

Gil. J. and M. Esteban 2000 Induction of apoptosis by the dsRNA-dependent protein kinase (PKR): mechanism of action. Apoptosis, 5: 107-114

Hossain, M., S. Shimizu, M. Matsuki, M. Imamura, S. Sakurai, and M. Iwami 2008 Expression of 20-hydroxyecdysone-induced genes in the silkworm brain and their functional analysis in post-embryonic development. Insect Biochem. Mol. Biol., 38: 1001-1007

Huang, J., Y. Zhang, M. Li, S. Wang, W. Liu, P. Couble, G. Zhao, and Y. Huang 2007 RNA interference-mediated silencing of the bursicon gene induces defects in wing expansion of silkworm. FEBS lett., 581: 697-701

Leach, D. R. 1994 Long DNA palindromes, cruciform structures, genetic instability and secondary structure repair. Bioessays, 6: $893-900$

Lee, J. M., M. Takahashi, H. Mon, Y. Nakajima, K. Koga, Y. Kawaguchi, and T. Kusakabe 2008 Construction of gene expression systems in insect cell lines using promoters from the silkworm, Bombyx mori. J Biotechnol., 133: 9-17

Lee, Y. S. and R. W. Carthew 2003 Making a better RNAi vector for Drosophila: use of intron spacers. Methods, 30: 322-329

Liu, W., F. Yang, S. Jia, X. Miao, and Y. Huang 2008 Cloning and characterization of Bmrunt from the silkworm Bombyx mori during embryonic development. Arch. Insect. Biochem. Physiol., 69: 47-59

Lopez-Martinez, G., M. Meuti, and D. L. Denlinger 2012 Rehydration driven RNAi: a novel approach for effectively delivering dsRNA to mosquito larvae. Methods Mol Biol., 843: $217-227$

Masumoto, M., T. Yaginuma, and T. Niimi 2009 Functional analysis of Ultrabithorax in the silkworm, Bombyx mori, using RNAi. Dev. Genes Evol., 219: 437-444

Miki, D. and K. Shimamoto 2004 Simple RNAi vectors for stable and transient suppression of gene function in rice. Plant Cell Physiol., 45: 490-495

Mon, H., T. Kusakabe, J. M. Lee, T. Maeda, Y. Kawaguchi, and K. Koga 2004 In vivo DNA double-strand breaks enhance gene targeting in the cultured silkworm cells. Comp. Biochem. Phys. B, 139: 99-106

Parrish, S., J. Fleenor, S. Xu, C. Mello, and A. Fire 2000 Functional anatomy of a dsRNA trigger: differential requirement for the two trigger strands in RNA interference. Mol. Cell, 6: 1077-1087

Pan, M. H., X. Y. Wang, C. L. Chai, C. D. Zhang, C. Lu, and Z. H. Xiang 2009 Identification and function of Abdominal-A in the silkworm, Bombyx mori. Insect Mol. Boil., 18: 155-160

Pfeifer, T. A., D. D. Hegedus, T. A. Grigliatti, and D. A. Theilmann 1997 Baculovirus immediate-early promoter-mediated expression of the Zeocin resistance gene for use as a dominant selectable marker in dipteran and lepidopteran insect cell lines. Gene, 188: 183-190

Quan, G. X., T. Kanda, and T. Tamura 2002 Induction of the white egg 3 mutant phenotype by injection of the doublestranded RNA of the silkworm white gene. Insect Mol. Boil., 11: $217-222$

Sakashita, K., T. Tatsuke, J. M. Lee, Y. Kawaguchi, and T. Kusakabe 2009 Sequence-nonspecific suppression of gene expression by double-stranded RNA in silkworm cultured cells. J. Insect Biotechnol. Sericol., 78: 33-37

Szulc, J., J. S. Wiznerowicz, M. Sauvain, D. Trono, and P. Aebischer 2006 A versatile tool for conditional gene expression and knockdown. Nat. Meth., 3: 109-116

Tabunoki, H., S. Higurashi, O. Ninagi, H. Fujii, Y. Banno, M. Nozaki, M. Kitajima, N. Miura, S. Atsumi, K. Tsuchida, H. Maekawa, and R. Sato 2004 A carotenoid-binding protein (CBP) plays a crucial role in cocoon pigmentation of silkworm (Bombyx mori) larvae. FEBS lett., 567: 175-178

Terenius, O., A. Papanicolaou, J. S. Garbutt, I. Eleftherianos, H Huvenne, S. Kanginakudru, M. Albrechtsen, C. An, J. L Aymeric, A. Barthel, P. Bebas, K. Bitra, A. Bravo, F. Chevalier, D. P. Collinge, C. M. Crava, R. A. de Maagd, B. Duvic, M. Erlandson, I. Faye, G. Felfoldi, H. Fujiwara, R. Futahashi, A S. Gandhe, H. S. Gatehouse, L. N. Gatehouse, J. M Giebultowicz, I. Gomez, C. J. Grimmelikhuijzen, A. T. Groot, F. Hauser, D. G. Heckel, D. D. Hegedus, S. Hrycaj, L. Huang, J. J. Hull, K. Iatrou, M. Iga, M. R. Kanost, J. Kotwica, C. Li, J. Li, J. Liu, M. Lundmark, S. Matsumoto, M. Meyering-Vos, P. J. Millichap, A. Monteiro, N. Mrinal, T. Niimi, D. Nowara, A. Ohnishi, V. Oostra, K. Ozaki, M. Papakonstantinou, A. Popadic, M.V. Rajam, S. Saenko, R.M. Simpson, M. Soberon, M. R. Strand, S. Tomita, U. Toprak, P. Wang, C. W. Wee, S. Whyard, W. Zhang, J. Nagaraju, R. H. Ffrench-Constant, S. Herrero, K. Gordon, L. Swevers, and G. Smagghe 2011 RNA interference in Lepidoptera: an overview of successful and unsuccessful studies and implications for experimental design. J. Insect Physiol., 57: 231-245

Tomimoto, K., M. Yamakawa, and H. Tanaka 2012 Construction of a long hairpin RNA expression library using Cre recombinase. J. Biotechnol., 30: In press

Yamamoto, M., M. Yamao, H. Nishiyama, S. Sugihara, S. Nagaoka, M. Tomita, K. Yoshizato, T. Tamura, and H. Mori 2004 New and highly efficient method for silkworm transgenesis using Autographa californica nucleopolyhedrovirus and piggyBac transposable elements. Biotechnol. Bioeng., 88: 849853 